\title{
Structure and function of the feeding apparatus in the common musk turtle Sternotherus odoratus (Chelonia, Kinosternidae)
}

\author{
Nikolay Natchev ${ }^{1,3}$, Egon Heiss ${ }^{1}$, Katharina Singer ${ }^{1}$, Stefan Kummer ${ }^{1}$, Dietmar Salaberger ${ }^{2}$, Josef Weisgram ${ }^{1}$ \\ ${ }^{1}$ Department of Theoretical Biology, University of Vienna, Althanstr. 14, A-1090 Vienna, Austria \\ ${ }^{2}$ Campus Wels, Upper Austria University of Applied Sciences, Stelzhammerstr. 23, 4600 Wels, Austria \\ ${ }^{3}$ E-mail:nikolay.natchev@univie.ac.at
}

Key words: feeding behaviour, head morphology, motion analysis, mud turtles, suction

\begin{abstract}
The present study examined the kinematic patterns of initial food uptake, food transport, pharyngeal packing and swallowing in the common musk turtle Sternotherus odoratus. These data are supplemented by morphological descriptions of the skull and the hyolingual complex. Although the hyoid is mainly cartilaginous, $S$. odoratus still use exclusively hydrodynamic mechanisms in prey capture and prey transport. The tongue is relatively small, with weakly developed intrinsic musculature. We propose that the elasticity of the hypoglossum and the hyoid body impacts the capability of $S$. odoratus to suction feed, but allows these turtles to effectively re-position the food items within the oropharyngeal cavity during transport, manipulation and pharyngeal packing. We standardised conditions in all feeding events by using food items of the same consistence and size, and by always offering the food at the same position at the bottom of the aquarium. Nonetheless, the measured kinematic values varied considerably. The duration of prey capture and prey transport cycles were relatively long in S. odoratus compared to other freshwater turtles studied so far. The initiation of hyoid retraction relative to the onset of jaw opening can be modulated not only in prey capture but also in prey transport cycles. In the common musk turtle, the jaw and hyoid movements apparently have a low level of integration.
\end{abstract}

\section{Contents}

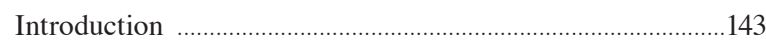

Material and methods ……………………………............. 144

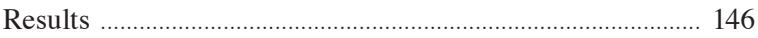

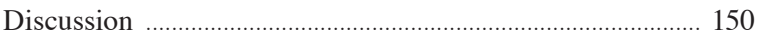

Acknowledgements ................................................................ 153

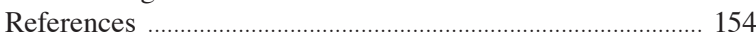

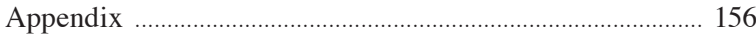

\section{Introduction}

According to Schwenk (2000), the feeding process in tetrapods consists of four main phases: 'prey capture' or 'ingestion'; 'food transport' (including manipulation); 'pharyngeal packing'; and 'swallowing' (or mammalian 'deglutition' (Smith, 1992)). In turtles, aquatic prey capture kinematics has been studied in pleurodirans (Van Damme and Aerts, 1997; Lemell and Weisgram, 1997; Lemell et al., 2002) and in marine (including one estuarine) cryptodirans (Bels and Renous, 1992; Bels et al., 1998). To date, food uptake kinematics have been analysed in details in only three freshwater cryptodirans; Chelydra serpentina (L., 1758) (Lauder and Prendergast, 1992), Terrapene carolina (L., 1758) (Summers et al., 1998) and Cuora amboinensis (Daudin, 1801) (Natchev et al., 2009). Information on the kinematics of all other main phases is scarce (Bels et al., 2008).

The origins and the phylogenetical relationships of stem and crown group turtles are still not completely understood (see Sterli, 2010). The oldest unquestioned stem turtle was an aquatic animal (Li et al., 2008). Some other stem turtle groups were terrestrial (Joyce and Gauthier, 2004; Scheyer and Sander, 2007), so the aquatic origin of the turtle stem is still contentious (see Lyson et al., 2010). Anyhow the feeding apparatus of the recent chelonians is secondarily adapted to aquatic feeding (Lauder and Prendergast, 1992). The turtles have developed aquatic feeding convergently with feeding systems in anamniotes. Lauder and Prendergast (1992) point to kinematic similarities in prey capture modes in some bony fishes, salamanders and the turtle $C$. serpentina. These authors explain the analogy in the underwater food uptake motoric by hydrodynamic constraints placed on prey capture due to the physical properties of the water as feeding media. The prey capture mechanism of $C$. serpentina was defined as 'ram feeding' - the prey is not sucked up into the oral cavity, but engulfed by the jaws in a rush forward strike of the cranocervical complex (Lauder and 
Prendergast, 1992). In tetrapods utilising 'bidirectional feeding' (Reilly and Lauder, 1992), any volume expansion of the oropharynx will result in a backward water flow relative to the skull. Van Damme and Aerts (1997) introduced the terms 'compensatory suction' and 'inertial suction' for turtles, retaining the term 'ram feeding' only for feeding systems with unrestrained water through-flow. According to Summers et al. (1998), the term 'compensatory suction' describes exactly the prey capture mode in cryptodirans, so the present study will not use the term 'ram feeding' for food uptake.

The neuromotor program of the underwater food transport is predicted to be conserved in the evolution of gnathostome feeding systems (Reilly and Lauder, 1990). In the cyclic model proposed by these authors for anamniotes, the jaw cycle is divided into a 'fast open' and 'fast close' phases, as hyoid retraction (expansion phase) starts simultaneously to the begin of jaw opening. The coincidence between hyoid retraction and jaw opening is regarded as a uniform pattern throughout tetrapods. This hypothesis is not always supported for turtles. The transport modes in turtles seem to be extraordinarily variable (Lemell and Weisgram, 1997; Lemell et al., 2002; Natchev et al., 2010). According to Aerts et al. (2001) the underwater transport in chelonians combines 'compensatory suction' and 'inertial suction'. Both mechanisms are termed 'intraoral-aquatic hyoid transport' (Bels et al., 2008). Nonetheless, some chelonians, even completely aquatic species, use tongue-based transport, which is termed 'intraoral-aquatic lingual transport' (Bels et al., 2008).

Except a brief description of feeding biomechanics in Claudius angustatus (Cope, 1985) (Weisgram, $1982,1985)$ information on the feeding kinematics in kinosternids is lacking. In this study, we describe the kinematics of the neck, jaws and hyoid complex based on high-speed film analysis during the whole aquatic feeding process in the omnivorous kinosternid Sternotherus odoratus (Latreille, 1801). These data are supplemented by morphological descriptions of the skull and hyolingual complex.

According to Heiss et al. (2008), the highest concentration of taste buds (tb) within the oropharynx in turtles is in areas where the first contact to the food occurs. Using the electron microscopic and histological techniques, we test this hypothesis in the common musk turtles. Herrel et al. (2002) categorised S. odoratus as a 'biter' and, according to these authors, turtles that can bite hard have a relatively low capacity to suction feed. We propose that in initial food uptake, the common musk turtle is not able to suck up food items deep within the oropharynx and that the first contact to the food will involve the jaws. Based on this analysis we predict the highest 'tb' concentration directly behind the horny 'bills' of the rhamphothecae.

In some turtles that use tongue-based food transport underwater, the lingual mucosa exhibits morphological similarities to those in purely terrestrial species. The dorsal lingual surface bears numerous vertical, high and slender lingual papillae. These increase the tongue surface and the interlocking effect between the tongue and the food during transport (see Natchev et al., 2010). The common musk turtle has a papillated dorsal tongue surface, but is not able to manipulate or transport food on land. The papillae are floppy, longitudinally orientated and often overlap each other. Because these papillae are highly vascularised, it is proposed that the main function of these structures is connected to aquatic gas exchange (Heiss et al., 2010). One of the main goals of the present study is to investigate the role of the papillated tongue of the common musk turtle in the aquatic food transport. Based on the design and orientation of the lingual papillae, we propose that they are physically incapable of withstanding shear forces. We hypothesise that $S$. odoratus uses exclusively hydrodynamic mechanisms to move food items within the oral cavity and toward the pharynx.

According to Bels et al. (1998), turtles with variable diet exhibit variability in their feeding kinematics and we expect the same for the common musk turtle. To test this hypothesis, we investigate statistically which variables of food uptake and food transport kinematic profiles exhibit similarities. We also test whether the kinematic patterns differ on an intra and inter-individual level. Special focus is devoted to analysing the coordination (sensu Wainwright et al.,2008) between the neck, hyoid and jaw movements. This is designed to test a predicted strength correlation between the movements of the elements of the feeding apparatus in underwater food transport in lower tetrapods (Reilly and Lauder, 1990).

\section{Material and methods}

The common musk turtle or stinkpot Sternotherus odoratus [the name Kinosternon odoratum is still used as a synonym (Bonin et al., 2006)] is an entirely aquatic species. It is widely distributed in the eastern USA, south to the Mexican border and north to Canada (Ernst and Barbour, 1989). This carnivorous to 
omnivorous species feeds on algae, parts of higher plants, carrion, insects, molluscs, crayfish and fish on the bottom of rivers, lakes and swamps (Pritchard, 1979; Ernst and Barbour, 1989; Bonin et al., 2006). There is only one short report on S. odoratus feeding on land in the wild (Newman, 1906). Under laboratory conditions we conducted experiments to motivate the animals to feed on the land area in the tank, but our specimens always failed to complete the feeding process (see Heiss et al., 2010).

The animals investigated here were obtained commercially and kept in a 3601 tank with $20 \%$ land and $80 \%$ water, and a $12 \mathrm{~h}$ dark $/ 12 \mathrm{~h}$ light cycle. They were fed with earthworms, fish pieces and turtle-food pellets from the pet trade. Animal care and treatment was in accordance with the 'Austrian National Protection of Animals Act'.

For morphological analysis, the turtles were anesthetized by intraperitoneally injecting sodium pentobarbital (Nembutal) and, after deep narcosis, decapitated. The heads were immersed immediately in fixation solution.

For computed tomography (CT), the heads of one juvenile (carapace length: $32.8 \mathrm{~mm}$ ), one subadult (carapace length: $69.3 \mathrm{~mm}$ ) and one adult animal (carapace length: $114 \mathrm{~mm}$ ) were immersed in $4 \%$ formaldehyde for two weeks prior to storage in $70 \%$ ethanol. The 3D data were generated using industrial X-ray Computed Tomography. During measurement projection, images were obtained using an a-Si matrix detector at several angular positions. Depending on the density, the atomic number and the irradiation length, different gray values occurred in these 2D images. A full 360 degree rotation typically yielded 720 images. At a voltage of $120 \mathrm{kV}$ and duration of 60 minutes, 990 projections were generated (voxel size $=27 \mu \mathrm{m}$ ). Surface and volume reconstructions were made using Amira 4.1 (Mercury Computer Systems, Chelmsford, MA, USA).

For scanning electron microscopy, two heads of juvenile turtles (carapace length: 30.6 and $34.2 \mathrm{~mm}$ ) were immersed for $24 \mathrm{~h}$ at room temperature in modified Karnovsky solution (2.5\% glutaraldehyde and 2\% formaldehyde in $0.1 \mathrm{M}$ cacodylate buffer; Karnovsky, 1965). After rinsing in $0.1 \mathrm{M}$ cacodylate buffer, the lower jaw was removed. Then, samples were postfixed in $0.5 \%$ osmium tetroxide for $2 \mathrm{~h}$ at $37^{\circ} \mathrm{C}$, washed in distilled water and treated with $25 \% \mathrm{HCl}$ at $40^{\circ} \mathrm{C}$ for $15 \mathrm{~min}$ to remove surface mucus. After repeated washing in distilled water, the samples were dehydrated in a graded ethanol and acetone series and dried in a crit- ical point drying machine (Polaron: Watford, UK). The dried samples were then coated with gold in an AGAR B7340 Sputtercoater (Agar Scientific Ltd, Stansted, UK) and observed in a Philips XL-20 scanning electron microscope (Philips, Eindhoven, the Netherlands).

For histological analysis, two juvenile (carapace length: 25.6 and $37.2 \mathrm{~mm}$ ) and two subadult (carapace length: 64.6 and $67.2 \mathrm{~mm}$ ) turtles were used. The heads were immersed in Bouin's fixative (Romeis, 1989) for 30 days, changing the solution twice a week. After complete fixation and decalcification, the upper jaw with the palatal region (frontal cut) and the lower jaw with the basis of the mouth were removed from the rest of the head and the cornified rhamphothecae were cut off. The samples were then dehydrated in a graded ethanol - isopropanol series and embedded in paraffin. After polymerisation, $7 \mu \mathrm{m}$ thin serial-sections were made on a Reichert-Jung 2030 rotation microtome (Reichert-Jung, Bensheim, Germany). The sections were mounted on glass slides and, after removing the paraffin, stained with Haematoxylin - Eosin, periodic acid Schiff (PAS) - Haematoxylin and Alcian blue Haematoxylin (Romeis, 1989; Kiernan, 2003). Digital photographic documentation was made using a Nikon Eclipse 800 light microscope (Nikon, Tokyo, Japan).

The longitudinal length of the tongue was measured in the two juvenile animals used for scanning electron microscopy. For these measurements the scanning electron micrographs of the tongue in dorsal view were used. The 'longitudinal lingual length' was taken as the distance between the lingual apex and the proximal end of the tongue opposite to the glottis. In the two subadult specimens used for histological analysis, the measurements were done with a calliper after the lower jaws were cut off. The measurements in one adult specimen (carapace length: $114 \mathrm{~mm}$ ) were made immediately after decapitation.

For filming aquatic feeding, the food items (pieces of epaxial musculature of fish) were offered in front of the animals on the bottom of a glass aquarium $(19 \times 7$ $\times 19 \mathrm{~cm}$ ) with a water depth of $12 \mathrm{~cm}$. The pieces of fish were positioned in front of the snout of the animals (distance to the tip of the snout 4-6 cm.). Often, after completing the feeding cycle, the turtles swam above the experimental area searching for other food particles. Before filming, the specimens were pushed gently backwards. The food size was calibrated based on the distance between the tip of the lower jaw and the point 'A' (Fig. 1) at the jaw articulation of every single turtle tested (this corresponds to almost $100 \%$ of the linear 
Fig. 1. Points used for kinematic analyses of feeding cycles of $S$. odoratus. A, ventral most point of tympanum (jaw articulation); C, anterior tip of carapace; $\mathrm{F}$, centre of mass of the feeding items; $\mathrm{H}$, basis of CB II on hyoid; L, anterior tip of lower jaw; $\mathrm{N}$, point 'zero' on the measurement board; S, dorsal margin of tympanum (the most dorsal point of the squamosal); U, anterior tip of upper jaw.

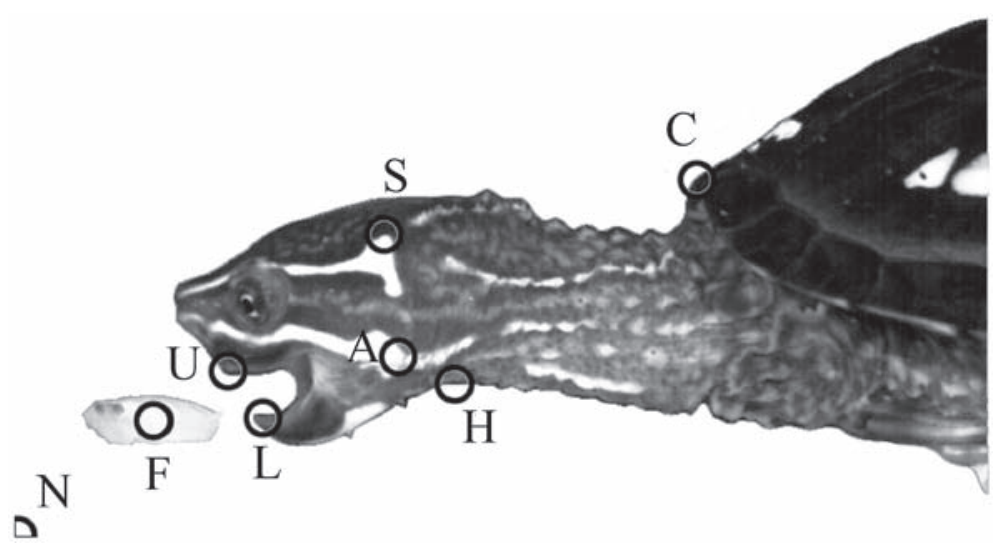

to compare feeding kinematic patterns are listed in Table 1. A MANOVA was performed to test differences regarding repeated measurements in the three individuals, differences between individuals, and differences between ingestion and transport cycles. The model residuals (MANOVA residuals) for each variable were checked using a K-S test and found to be normally distributed. Food uptake (ingestion) cycles from all specimens were aligned at reaching peak gape, and the mean profiles $( \pm$ SEM $)$ of the movements of the gape, hyoid and neck were calculated and plotted. Mean transport kinematic profiles $( \pm$ SEM) of gape, hyoid and neck were calculated separately for every individual, as the cycles were aligned at reaching peak gape.

Additionally, correlations between movements of head, jaws and hyoid were analyzed in both ingestion and transport phases. The movements (i.e. the changes in distance) were correlated over time for each recording. Only significant correlations above 0.3 are named and considered to have real impact on the examined material. Correlations between movements of head, jaws and hyoid were analyzed in both ingestion and transport modes; only significant correlations $>0.3$ are presented and considered to truly impact the material examined.

\section{Results}

The skull of $S$. odoratus is flat and elongated with a prominent supraoccipital ridge and wide and high temporal arches. The rhamphothecae are hooked, massive and, as typical for most kinosternids, the edges are smooth and blunt. The palate forms no dorsal flexure (Fig. 2c). For detailed analysis of the morphology and development in the postnatal scull see Bever (2009). The

IBM, Chicago, USA) software. The 13 variables used 
Table 1. Kinematic variables from aquatic feeding events in S. odoratus. Values are means \pm SD with associated significance values. $\mathrm{t}_{\mathrm{FO}}$ - fast opening; $\mathrm{t}_{\mathrm{PG}}$ - time to peak gape; $\mathrm{t}_{\mathrm{MG}}$ - MG-phase duration; $\mathrm{t}_{\mathrm{FC}}$ - fast closing duration; $\mathrm{t}_{\mathrm{D}}$ - total cycle duration; $\mathrm{t}_{\mathrm{HR}}$ - hyoid retraction duration; $\mathrm{t}_{\mathrm{NE}}$ - neck extension duration; $\mathrm{t}_{\mathrm{HFOB}}$ - hyoid retraction delay to fast opening begin; $\mathrm{t}_{\mathrm{HFOE}}$ - time interval of hyoid retraction onset relative to jaw opening end; $\mathrm{V}_{\mathrm{FO}}$ - fast opening velocity; $\mathrm{V}_{\mathrm{FC}}$ - fast closing velocity; $\mathrm{V}_{\mathrm{HR}}$ - hyoid retraction velocity; $\mathrm{V}_{\mathrm{NE}}$ - neck extension velocity; *Significant differences $(\alpha=0.05)$ among individuals in the ingestion phase $\left(P^{1}\right)$, among individuals in the transport phase $\left(P^{2}\right)$ and between ingestion and transport mode $\left(P^{3}\right)$.

\begin{tabular}{|c|c|c|c|c|c|c|c|c|c|}
\hline \multirow[b]{2}{*}{ Variables } & \multicolumn{4}{|l|}{ Ingestion } & \multicolumn{5}{|l|}{ Transport } \\
\hline & $\begin{array}{l}\text { individual } 1 \\
(n=7)\end{array}$ & $\begin{array}{l}\text { individual } 2 \\
(n=6)\end{array}$ & $\begin{array}{l}\text { individual } 3 \\
(n=6)\end{array}$ & $P^{1}$ & $\begin{array}{l}\text { individual } 1 \\
(\mathrm{n}=15)\end{array}$ & $\begin{array}{l}\text { individual } 2 \\
(n=16)\end{array}$ & $\begin{array}{l}\text { individual } 3 \\
(\mathrm{n}=8)\end{array}$ & $P^{2}$ & $P^{3}$ \\
\hline $\mathrm{t}_{\mathrm{FO}}(\mathrm{s})$ & $\begin{array}{l}0.055 \pm 0.008 \\
(\mathrm{n}=6)\end{array}$ & $\begin{array}{l}0.055 \pm 0.005 \\
(\mathrm{n}=3)\end{array}$ & $\begin{array}{l}0.048 \pm 0.024 \\
(\mathrm{n}=5)\end{array}$ & 0.695 & $\begin{array}{l}0.046 \pm 0.014 \\
(n=15)\end{array}$ & $\begin{array}{l}0.041 \pm 0.015 \\
(\mathrm{n}=16)\end{array}$ & $\begin{array}{l}0.034 \pm 0.008 \\
(\mathrm{n}=8)\end{array}$ & $0.009^{*}$ & $0.031^{*}$ \\
\hline $\mathrm{t}_{\mathrm{PG}}(\mathrm{s})$ & $\begin{array}{l}0.425 \pm 0.159 \\
(\mathrm{n}=7)\end{array}$ & $\begin{array}{l}0.358 \pm 0.308 \\
(n=6)\end{array}$ & $\begin{array}{l}0.201 \pm 0.105 \\
(n=6)\end{array}$ & 0.12 & $\begin{array}{l}0.092 \pm 0.064 \\
(\mathrm{n}=15)\end{array}$ & $\begin{array}{l}0.144 \pm 0.156 \\
(n=16)\end{array}$ & $\begin{array}{l}0.085 \pm 0.102 \\
(n=8)\end{array}$ & 0.148 & $0.001^{*}$ \\
\hline $\mathrm{t}_{\mathrm{MG}}(\mathrm{s})$ & $\begin{array}{l}0.034 \pm 0.0062 \\
(n=7)\end{array}$ & $\begin{array}{l}0.016 \pm 0.007 \\
(n=6)\end{array}$ & $\begin{array}{l}0.015 \pm 0.010 \\
(\mathrm{n}=6)\end{array}$ & $0.002^{*}$ & $\begin{array}{l}0.007 \pm 0.013 \\
(\mathrm{n}=5)\end{array}$ & $\begin{array}{l}0.000 \pm 0.000 \\
(\mathrm{n}=0)\end{array}$ & $\begin{array}{l}0.005 \pm 0.008 \\
(n=2)\end{array}$ & 0.161 & $<0.001^{*}$ \\
\hline $\mathrm{t}_{\mathrm{FC}}(\mathrm{s})$ & $\begin{array}{l}0.056 \pm 0.022 \\
(\mathrm{n}=7)\end{array}$ & $\begin{array}{l}0.049 \pm 0.03 \\
(\mathrm{n}=6)\end{array}$ & $\begin{array}{l}0.048 \pm 0.017 \\
(\mathrm{n}=6)\end{array}$ & 0.71 & $\begin{array}{l}0.071 \pm 0.04 \\
(n=15)\end{array}$ & $\begin{array}{l}0.054 \pm 0.029 \\
(\mathrm{n}=16)\end{array}$ & $\begin{array}{l}0.046 \pm 0.013 \\
(\mathrm{n}=8)\end{array}$ & $0.002^{*}$ & 0.48 \\
\hline $\mathrm{t}_{\mathrm{D}}(\mathrm{s})$ & $\begin{array}{l}0.515 \pm 0.169 \\
(n=7)\end{array}$ & $\begin{array}{l}0.423 \pm 0.34 \\
(\mathrm{n}=6)\end{array}$ & $\begin{array}{l}0.265 \pm 0.112 \\
(\mathrm{n}=6)\end{array}$ & 0.101 & $\begin{array}{l}0.162 \pm 0.09 \\
(n=15)\end{array}$ & $\begin{array}{l}0.198 \pm 0.182 \\
(n=16)\end{array}$ & $\begin{array}{l}0.131 \pm 0.095 \\
(n=8)\end{array}$ & $0.015^{*}$ & $0.001^{*}$ \\
\hline $\mathrm{t}_{\mathrm{HR}}(\mathrm{s})$ & $\begin{array}{l}0.035 \pm 0.011 \\
(\mathrm{n}=7)\end{array}$ & $\begin{array}{l}0.033 \pm 0.014 \\
(n=6)\end{array}$ & $\begin{array}{l}0.033 \pm 0.005 \\
(\mathrm{n}=6)\end{array}$ & 0.448 & $\begin{array}{l}0.038 \pm 0.015 \\
(\mathrm{n}=15)\end{array}$ & $\begin{array}{l}0.033 \pm 0.018 \\
(\mathrm{n}=16)\end{array}$ & $\begin{array}{l}0.044 \pm 0.016 \\
(n=8)\end{array}$ & $0.025^{*}$ & 0.103 \\
\hline $\mathrm{t}_{\mathrm{NE}}(\mathrm{s})$ & $\begin{array}{l}0.093 \pm 0.048 \\
(\mathrm{n}=7)\end{array}$ & $\begin{array}{l}0.07 \pm 0.038 \\
(\mathrm{n}=5)\end{array}$ & $\begin{array}{l}0.075 \pm 0.018 \\
(\mathrm{n}=6)\end{array}$ & 0.886 & $\begin{array}{l}0.056 \pm 0.03 \\
(n=9)\end{array}$ & $\begin{array}{l}0.04 \pm 0.013 \\
(\mathrm{n}=11)\end{array}$ & $\begin{array}{l}0.06 \pm 0.022 \\
(\mathrm{n}=8)\end{array}$ & 0.125 & 0.37 \\
\hline $\mathrm{t}_{\mathrm{HFOB}}(\mathrm{s})$ & $\begin{array}{l}0.060 \pm 0.007 \\
(n=6)\end{array}$ & $\begin{array}{l}0.062 \pm 0.006 \\
(n=3)\end{array}$ & $\begin{array}{l}0.047 \pm 0.021 \\
(\mathrm{n}=5)\end{array}$ & 0.176 & $\begin{array}{l}0.023 \pm 0.007 \\
(n=15)\end{array}$ & $\begin{array}{l}0.021 \pm 0.01 \\
(n=16)\end{array}$ & $\begin{array}{l}0.017 \pm 0.004 \\
(\mathrm{n}=8)\end{array}$ & 0.154 & $<0.001^{*}$ \\
\hline $\mathrm{t}_{\mathrm{HFOE}}(\mathrm{s})$ & $\begin{array}{l}0.006 \pm 0.007 \\
(n=7)\end{array}$ & $\begin{array}{l}0.003 \pm 0.008 \\
(n=6)\end{array}$ & $\begin{array}{l}0.001 \pm 0.007 \\
(\mathrm{n}=6)\end{array}$ & 0.321 & $\begin{array}{l}-0.022 \pm 0.01 \\
(n=15)\end{array}$ & $\begin{array}{l}-0.14 \pm 0.004 \\
(\mathrm{n}=16)\end{array}$ & $\begin{array}{l}-0.017 \pm 0.006 \\
(\mathrm{n}=8)\end{array}$ & $0.007^{*}$ & $<0.001^{*}$ \\
\hline $\mathrm{V}_{\mathrm{FO}}(\mathrm{cm} / \mathrm{s})$ & $\begin{array}{l}4.795 \pm 1.082 \\
(n=6)\end{array}$ & $\begin{array}{l}5.89 \pm 4.747 \\
(n=3)\end{array}$ & $\begin{array}{l}4.851 \pm 3.081 \\
(n=5)\end{array}$ & 0.453 & $\begin{array}{l}7.195 \pm 3.31 \\
(n=15)\end{array}$ & $\begin{array}{l}15.316 \pm 5.159 \\
(\mathrm{n}=16)\end{array}$ & $\begin{array}{l}16.587 \pm 7.29 \\
(n=8)\end{array}$ & $0.008^{*}$ & 0.127 \\
\hline $\mathrm{V}_{\mathrm{FC}}(\mathrm{cm} / \mathrm{s})$ & $\begin{array}{l}9.408 \pm 3.587 \\
(n=7)\end{array}$ & $\begin{array}{l}14.517 \pm 5.37 \\
(n=6)\end{array}$ & $\begin{array}{l}9.18 \pm 1.543 \\
(n=6)\end{array}$ & $0.015^{*}$ & $\begin{array}{l}3.659 \pm 3.365 \\
(n=15)\end{array}$ & $\begin{array}{l}11.769 \pm 4.027 \\
(n=16)\end{array}$ & $\begin{array}{l}7.067 \pm 2.295 \\
(\mathrm{n}=8)\end{array}$ & $<0.001^{*}$ & $0.003^{*}$ \\
\hline $\mathrm{V}_{\mathrm{HR}}(\mathrm{cm} / \mathrm{s})$ & $\begin{array}{l}10.642 \pm 3.932 \\
(\mathrm{n}=7)\end{array}$ & $\begin{array}{l}8.554 \pm 3.292 \\
(n=6)\end{array}$ & $\begin{array}{l}8.694 \pm 2.77 \\
(n=6)\end{array}$ & 0.505 & $\begin{array}{l}5.477 \pm 2.511 \\
(n=15)\end{array}$ & $\begin{array}{l}12.869 \pm 7.62 \\
(n=12)\end{array}$ & $\begin{array}{l}8.285 \pm 1.958 \\
(n=8)\end{array}$ & $0.001^{*}$ & 0.56 \\
\hline $\mathrm{V}_{\mathrm{NE}}(\mathrm{cm} / \mathrm{s})$ & $\begin{array}{l}4.933 \pm 2.742 \\
(n=7)\end{array}$ & $\begin{array}{l}7.89 \pm 1.449 \\
(n=5)\end{array}$ & $\begin{array}{l}9.663 \pm 1.811 \\
(n=6)\end{array}$ & 0.91 & $\begin{array}{l}1.876 \pm 4.42 \\
(n=9)\end{array}$ & $\begin{array}{l}4.819 \pm 6.927 \\
(n=11)\end{array}$ & $\begin{array}{l}6.753 \pm 2.019 \\
(n=8)\end{array}$ & $<0.001^{*}$ & 0.187 \\
\hline
\end{tabular}

tongue is small (longitudinal length: in two juvenile 1.16 and $1.24 \mathrm{~mm}$; in two subadult -4.13 and $4.42 \mathrm{~mm}$; in one adult - $7.24 \mathrm{~mm}$ ) with weakly developed proper musculature. The dorsal surface of the tongue is amplified due to the formation of floppy papillae (Fig. 2f).

In juvenile and subadult specimens the hypoglossum, hyoid body, epibranchials I and second hyoid horn are completely cartilaginous. Only the ceratobranchials I are ossified (Fig. 2a-c, e). The CT analysis demonstrated that the hyoid complex remains mainly cartilaginous even in older individuals (Fig. 2b). There are only two pairs of ossifications on the hyoid corpus (at the basis of ceratobranchials I and II).

Scanning electron microscopy revealed the occurrence and distribution of taste buds (tb). Tb's were identified based on their typical taste pore with large microvilli in the centre (Fig. 2d). Tb's were found throughout the oropharyngeal cavity: from the wellkeratinized anterior-most mouth region to the posterior-most end of the pharynx. Most tb's in juvenile and subadult turtles were counted on the anterior palate (anterior to the choanae) and on the anterior floor of the mouth.

When feeding on small pieces of fish, the feeding process included the initial food uptake cycle, zero to four (average $\pm \mathrm{SD}=2.054 \pm 1.08$ ) transport cycles, two to six (average $\pm \mathrm{SD}=4.1 \pm 1.3$ ) pharyngeal packing cycles, followed by swallowing. When a food item was offered the turtles swam toward the food and stopped their forward locomotion when the tip of the lower jaw was at $0.48 \pm 0.17 \mathrm{~cm}$ from the fish. Food uptake started with hyoid elevation followed by jaw 

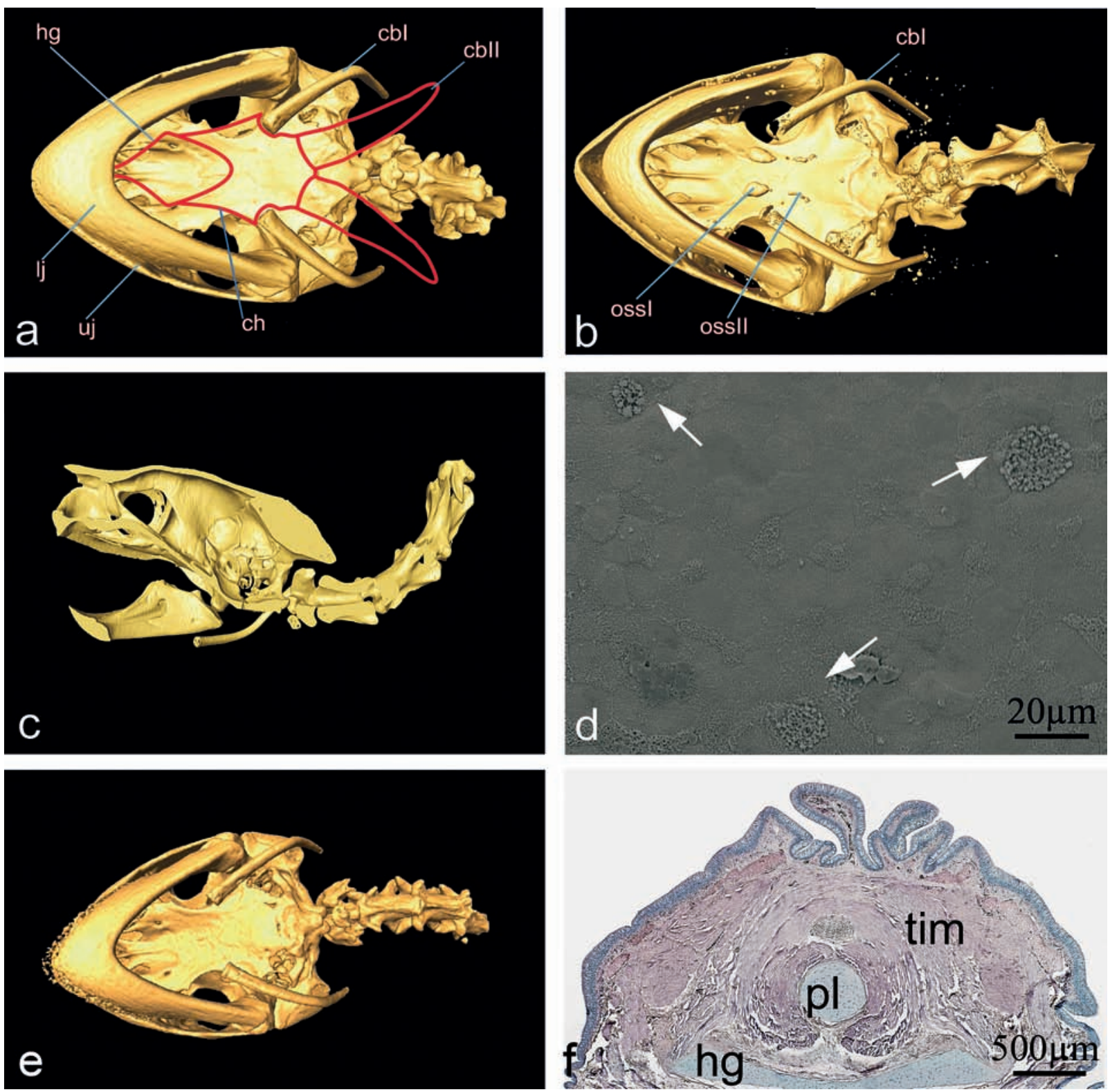

Fig. 2. Head morphology of S. odoratus. a, CT-scan after Amira 4.1 reconstruction from ventral with schematic illustration of hyoid complex (subadult): cbI, ceratobranchiale I; cbII, ceratobranchiale II, ch, corpus hyoidei; hg, hypoglossum; lj, lower jaw; uj, upper jaw; b, CT-scan after Amira 4.1 reconstruction from ventral (adult): cbI, ceratobranchiale I; ossI, island of ossification at basis of cbI; ossII, island of ossification at basis of cbII; c, CT-scan after Amira 4.1 reconstruction sagittal section (subadult); d, Scanning electron micrograph at medium magnification showing three neighbouring taste buds (tb). tb's are recognized by their taste pores containing large microvilli (arrows); e, CT-scan after Amira 4.1 reconstruction from ventral (juvenile); f, Light micrograph cross-section of the tongue of a subadult $S$. odoratus slightly anterior to the glottis. Note the weakly developed intrinsic musculature: hg, hypoglossum; pl, processus lingualis; tim, tongue intrinsic musculature;

opening. The body was almost entirely motionless. In most of our sequences (14 of 19) we were able to detect a separation of 'slow jaw open (SO)' and 'fast jaw open (FO)' phases. In 5 other films, the gape increased grad- ually and no discrete phases were recognized prior to reaching 'peak gape'. During jaw opening the head rotated ventrally. In 5 of our sequences the hyoid retraction started prior reaching peak gape (Fig. 4b). In 


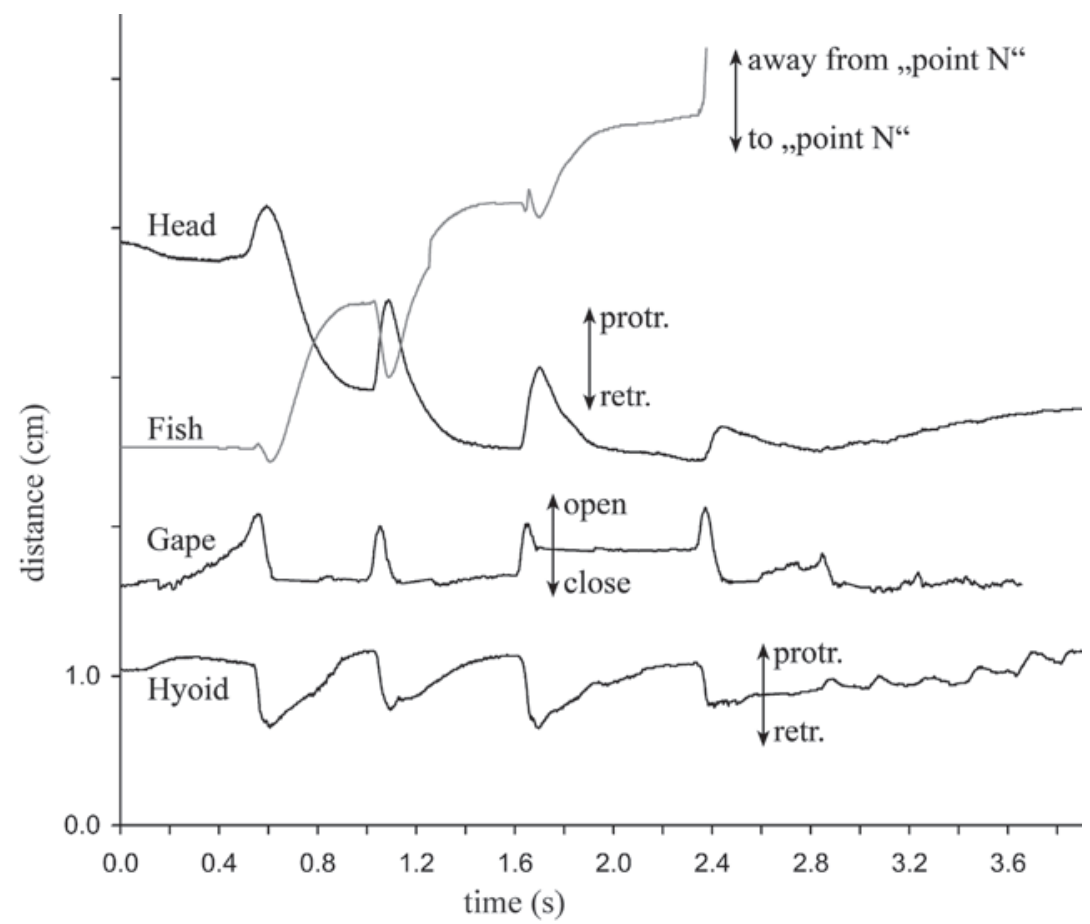

Fig. 3. Kinematic profiles from an aquatic feeding event in S. odoratus, including one food uptake, three food transport cycles, four pharyngeal packing and two swallowing cycles based on high-speed film (500 fr/s): protr., protraction; retr., retraction; dors., dorsal; ventr., ventral.
14 cycles the first detectable retraction of the hyoid complex started during a static gape phase where the jaw amplitude remained at its maximum for a period of time (here termed MG-phase) (Fig. 4c). The MGphase (present in all 19 'prey capture' events) was followed by fast jaw closing. The food item was actively sucked up into the mouth due to the pharyngeal expansion, but was often (detected in 12 of 19 films) pushed again slightly forwards during jaw closure.

Prey transport cycles started with hyoid protraction followed by jaw opening. In 28 of 39 food transport events, the neck extended rapidly during jaw opening. In all sequences the hyoid retraction started prior to reaching peak gape (Figs 3, 5, 6). MG-phase was detected in 7 of our sequences. In 11 transport cycles the cranium remained motionless or was ventrally rotated rather than protracted.

The 13 kinematic variables used (Tab. 1) revealed no significant differences between repetition of measurements within the single individuals (MANOVA Wilk's $\lambda, F=0.88, P=0.785$ ), or between individuals in food ingestion (MANOVA Wilk's $\lambda, F=3.486$, $P=0.116)$. Highly significant differences were detected between individuals in the transport phase (MANOVA Wilk's $\lambda, F=79,919, P<0.001)$ and between ingestion and transport phase (MANOVA Wilk's $\lambda, F=15.653$, $P<0.001)$. This means that even if individuals maintain similar kinematic patterns through repeated cycles, the differences between individuals are significant (at least in transport); the feeding patterns between ingestion and transport also differed significantly.

Individual kinematic differences in food transport were additionally demonstrated through a conical centroid plot (Fig. 7). Variables 'total duration' $\left(\mathrm{t}_{\mathrm{D}}\right)$ and 'time fast open' $\left(t_{\mathrm{FO}}\right)$ loaded positively and variables 'fast closing velocity' $\left(\mathrm{V}_{\mathrm{FC}}\right)$, 'time interval of hyoid retraction onset relative to fast opening end' $\left(\mathrm{t}_{\mathrm{HFOE}}\right)$ and 'hyoid retraction velocity' $\left(\mathrm{V}_{\mathrm{HR}}\right)$ loaded negatively to the first canonical axis, while variable 'hyoid retraction delay to fast opening begin' $\left(t_{\mathrm{HFOB}}\right)$ loaded positively and variables 'neck extension velocity' $\left(\mathrm{V}_{\mathrm{NE}}\right)$ and 'hyoid retraction duration' $\left(\mathrm{t}_{\mathrm{HR}}\right)$ loaded negatively to the second canonical axis. Together, the axes explained $100 \%$ of the variance among individuals.

When testing for correlation between movements of head, gape and hyoid during ingestion, highly significant correlations were found between head and hyoid in animal 1 and 2; between head and gape in none; and between hyoid and gape in animal 1 and 3 . When testing the same parameters for correlation in the transport mode, only the head and hyoid movements in animal 3 were highly significantly correlated. All other correlations were not significant or below 0.3 (i.e. below real relevance). 

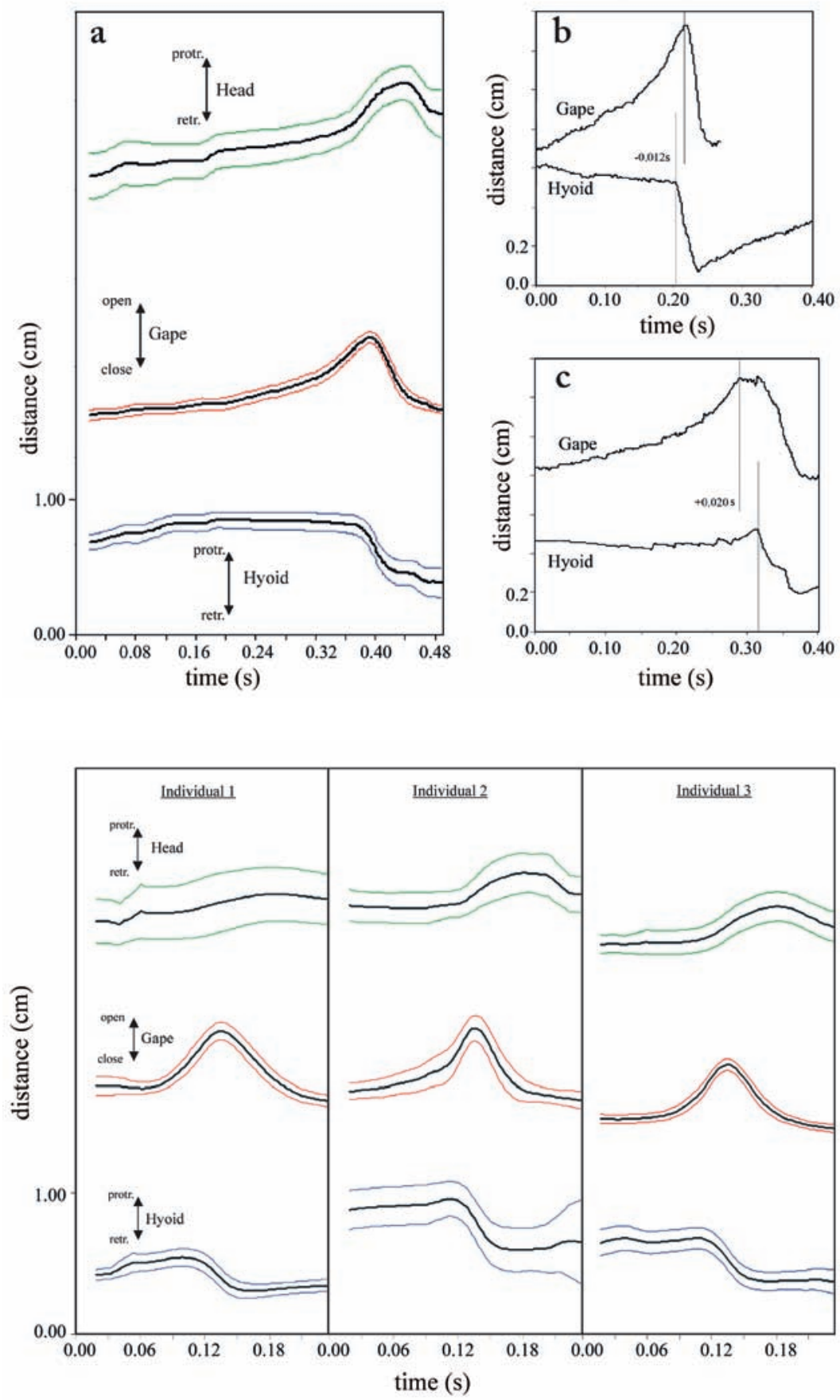

Fig. 4. Kinematic patterns in aquatic food uptake in S. odoratus. a, kinematic profiles from aquatic food uptake cycles $(\mathrm{n}=19)$ in three $S$. odoratus specimens based on high-speed films (500 fr/s). Black lines: mean kinematic profile. Coloured lines: standard error of mean $( \pm$ SEM $)$, calculated from all other profiles, aligned synchronised on the first peak gape frame; $b$, food uptake - minimum delay of hyoid retraction start to reaching peak gape (hyoid retraction starts prior to reaching peak gape); c, food uptake - maximum delay of hyoid retraction start to reaching peak gape (hyoid retraction starts during maximal gape phase); protr., protraction; retr., retraction.
Fig. 5. Kinematic patterns in aquatic food transport in three $S$. odoratus specimens based on high-speed films (500 $\mathrm{fr} / \mathrm{s})$. Black lines: mean kinematic profile. Coloured lines: standard error of mean $( \pm$ SEM), calculated from all profiles per individual, aligned synchronised on the first peak gape frame; protr., protraction; retr., retraction.

\section{Discussion}

According to Bever $(2007,2009)$, features associated with the feeding apparatus are the most variable cranial structures for both continuous and discrete characters in S.odoratus. One explanation for the postnatal morphological variations in the continuous characters of the skull is a potential dietary shift during ontogenetic development (Pritchard, 1979; Bonin et al., 2006; Bever, 2007, 2009). Correlations between dietary shift and ontogenetic changes in the skull morphology and biomechanics are well documented in the loggerhead 
musk turtle Sternotherus minor (Agassiz, 1857) (Pfaller, 2009; Pfaller et al., 2010). Based on our morphological investigations in $S$. odoratus using CT, we demonstrate that no major change takes place in the ossification rate of the hyoid complex during transition from juvenile to adult. The hyoid corpus remains largely cartilaginous even in older animals. A heavily ossified hypoglossum and hyoid body are predicted in all turtles using predominantly suction feeding under water (Bramble, 1973; Bramble and Wake, 1985; Van Damme and Aerts, 1997; Lemell et al., 2000, 2002, 2010). A cartilaginous hyoid body (or lingual processus) in extant chelonians is associated with a greater role of the tongue in feeding (Bramble and Wake, 1985; Wochesländer et al., 1999; Richter et al., 2007; Natchev et al., 2009, 2010). According to Pfaller (2009) the durophagous (feeding on hard-shelled snails) loggerhead musk turtle possesses a relatively large, muscular and mobile tongue and a weakly developed hyoid apparatus. That author proposes that the large tongue helps to orally manipulate the snails. The common musk turtle utilises exclusively hydrodynamic mechanisms in prey capture and prey transport, so one could expect more rigid hyoid complex. Our interpretation is that the elastic hyoid body allows these turtles to increase the plasticity in the movements of the hyolingual complex. The common musk turtle feeds on hard prey, including insects, snails and mussels. That kind of hard prey has to be killed, crushed, eventually cleaned or sized, so a bendable hyoid basis would facilitate the rostro-caudal and caudo-rostral reposition of the food item within the oropharynx during the transport (manipulation) phase. We cannot completely exclude that the smaller and elastic hyoid is a remnant of the ancestral state, but as the common ancestor of all extant turtles was an aquatic species (see Joyce and Gauthier, 2004) and a well-ossified hyoid is expected in aquatic living turtles (see Bramble and Wake, 1985), it is logical to propose that the reduced ossification of the hyoid in S. odoratus represents an adaptation. Within kinosternids are found also species with highly ossified hyoid apparati (Weisgram, 1985).

Our prey capture sequences revealed that the common musk turtles actively sucked up the food items by somewhat expanding the oropharyngeal cavity. Initial movement of the food toward the oropharynx was detected as the fish pieces were already within the plane of the gaping mouth. In only one film the initial food uptake event (food ingestion) resembled pure inertial suction - the cranium remained static as the prey moved into the mouth. Herrel et al. (2002) hypothesise a trade-off between the bite performance and the capacity to suction feed in turtles. Those authors report a bite force of $30.72 \pm 19.20 \mathrm{~N}$ in S. odoratus and include this species in the 'biters' group of turtles. Prior to the 'final head fixation' (see Lemell and Weisgram, 1997) S. odoratus must approach the food item to a very close distance (several millimetres). Apparently, outside the margins of the jaws, the common musk turtles are unable to create effective suction forces. Although suction performance was not quantified in the present study, these observations seem to support the hypothesis of Herrel et al. (2002), that turtles able to bite hard have a relatively low capacity to suction feed (or at least to capture prey via suction).

Kinematic patterns of the gape and neck varied considerably. We therefore conclude that $S$. odoratus adjusts its food uptake behaviour to every single feeding situation, depending on the position of the food relative to the jaws. As the pieces of fish used in our experiments usually remained under the 'beak' during jaw opening, the animals apparently have no permanent visual contact with the food items. Perhaps the motoric of the feeding apparatus is coordinated in combined response to visual and olfactory feedback, and to the tactile 'cirri' (see Winokur, 1982).

In contrast to the most cryptodiran turtles studied to date (Lauder and Prendergast, 1992; Bels et al., 1998; Summers et al., 1998; Bels et al., 2008), hyoid retraction in the common musk turtle starts shortly before or even after reaching peak gape during food uptake (Figures 3,4). This behaviour [similar to the behaviour described in C. amboinensis (Natchev et al., 2009)] probably reflects the relatively poor capacity of $S$. odoratus to suction feed. The abrupt retraction of the relatively small and elastic hyoid complex cannot produce the high suction forces found in species like e.g. Chelus fimbriata (Schneider, 1783) (Lemell et al., 2002). The common musk turtle lacks the skinny 'cheeks' lateral to the gaping mouth [as found in some turtles specialized in suction feeding (Lemell et al., 2002)], so the water flow cannot be directed so precisely toward the oropharynx. In our interpretation, the maintain of largest possible gape during the initiation of suction and the start of head protraction increase the potential for successful procurement of the food item.

When feeding on fish pieces, the common musk turtle transported the food items using intraoralaquatic hyoid transport' (see Bels et al., 2008). The tongue played a subordinate, or perhaps no role in food 


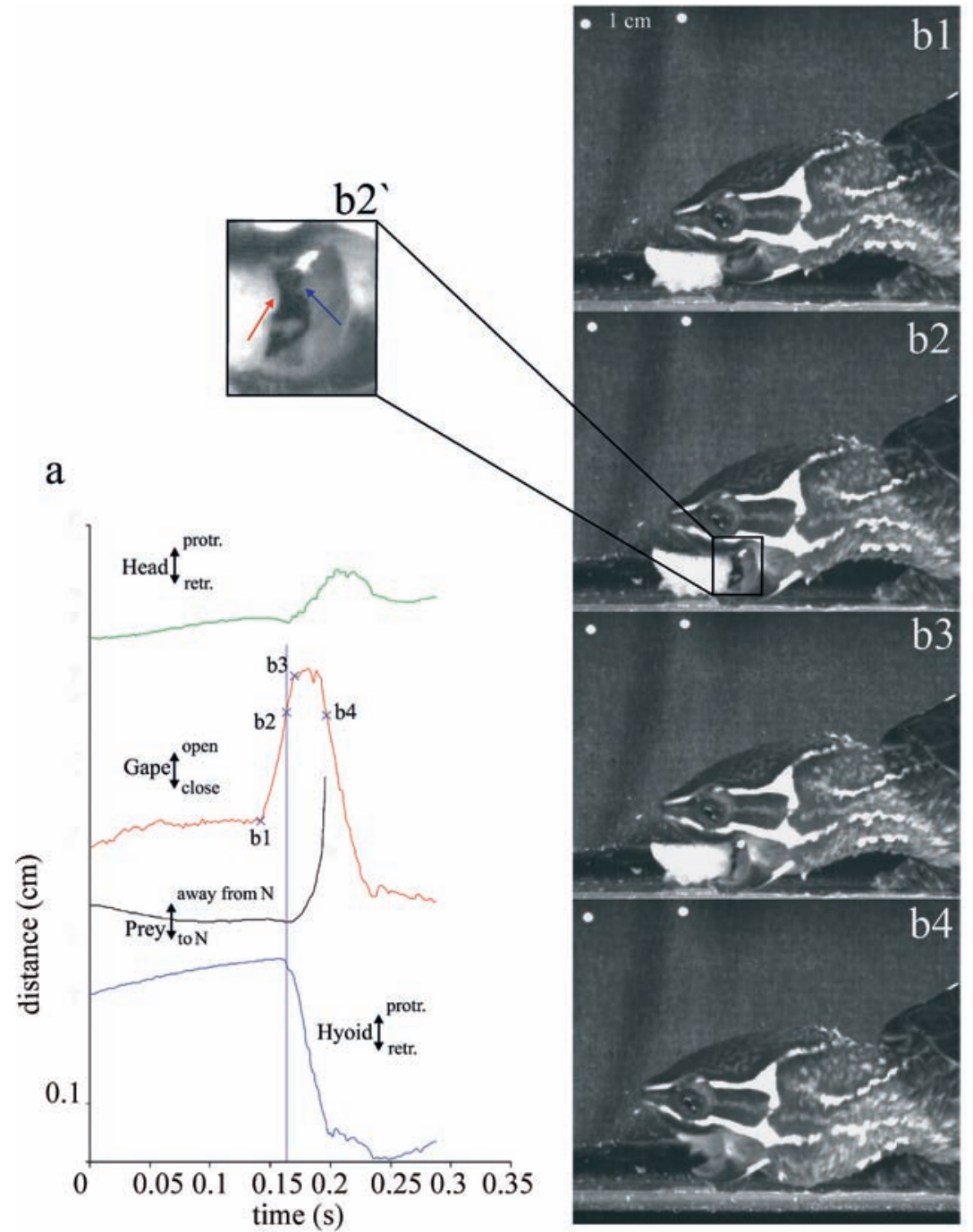

Fig. 6. Aquatic food transport in S. odoratus. a. Kinematic profiles based on a high-speed film sequence (500 fr/s): green line represents the kinematic profile of the head; red line represents the kinematic profile of the gape; black line represents the movement of the food item relative to point 'N' (see Fig. 1); blue line represents the kinematic profile of the hyoid; blue crosses correspondent to the selected frames from the highspeed film sequence; blue vertical line represents the start of the hyoid retraction. b. Selected frames from a high speed-film sequence: b1, start of fast open phase; b2, start of the hyoid retraction; b2', higher magnification representing the tip of the tongue (blue arrow) and the most posterior point on the food item indicated by the red arrow (note that the tongue does not have a contact with the food); b3, peak gape; b4, the last frame on which the point ' $F$ ' (see Fig. 1) was visible. transport (see Fig. 6). In $72 \%$ of our sequences, prey transport involved compensatory suction. As the neurocranium remained fully static in the rest of the food transport events, the turtles apparently relied on pure inertial suction in these cases. Our film sequences reveal no discrete slow phase during jaw opening, but there is variability in the delay of the start of hyoid retraction to the start of gape increase (see Tab. 1; Fig. 5 ). The beginning of pharyngeal expansion in S. odoratus does not correspond strictly to the start of the jaw open phase as predicted from the model of Reilly and Lauder (1990). In some turtles that can feed under water and have relatively well-developed tongues, hyoid retraction starts shortly before or even after reaching peak gape. The Amboina box turtle C.amboinen- sis uses its tongue to fix the prey against the palate during jaw opening (Natchev et al., 2009), whereas the Indochinese box turtle Cuora galbinifrons (Bourret, 1939 ) is able to fix prey to the dorsal tongue surface during gape increase (Natchev et al., 2010). This enables these two species to hold the food items within the oral cavity even at maximum gape. The common musk turtle has a weak intrinsic lingual musculature and the tongue papillae are not designed to support food transport (Heiss et al., 2010), so the tongue cannot be used to fix the food. For prey transport $S$. odoratus uses exclusively hydrodynamic mechanisms (as demonstrated in Fig. 6). Hyoid retraction must start after the prey is released from the rhamphothecae during jaw opening, but before the prey can escape or float out of the oral 


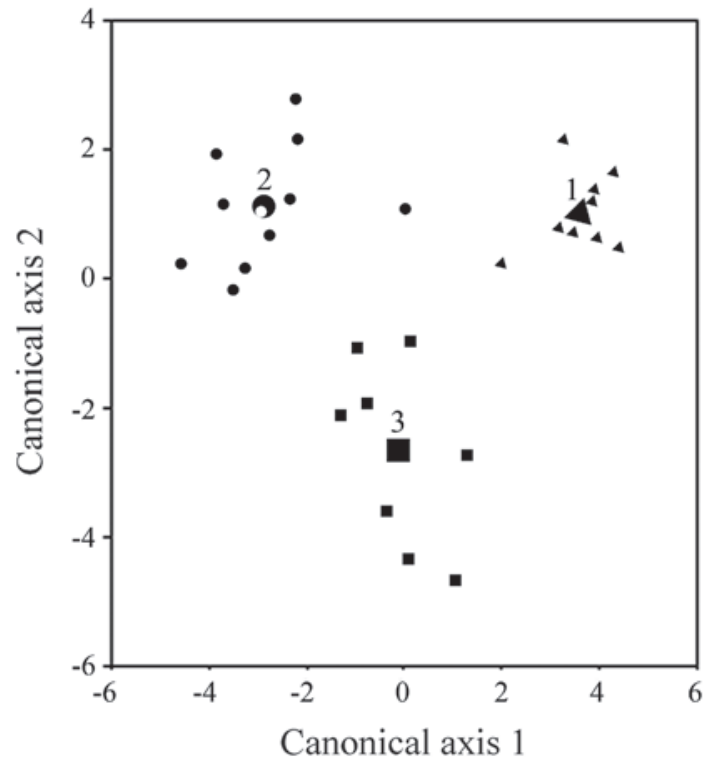

Fig. 7. Conical centroid plots of kinematic variables of food transport in three $S$. odoratus specimens. Centroids plotted for each individual (large figures) and measurement repetition (small figures).

cavity. Due to the numerous taste buds on the oropharyngeal surfaces (Fig. 2d), we propose that besides mechanoreceptor input, the chemosensorial feedback helps coordinate the movements of the feeding apparatus during transport. Tb's are most highly concentrated in the anterior palate and the anterior floor of the mouth. This anterior concentration enables a fast motoneural response of the type 'eat it or leave it' (Heiss et al., 2008) because the first prey contact occurs there. In the natural environment, the negative response (rejection) may be crucial: the benefit of avoiding harmful food is self-evident (Schwenk, 1985; Berkhoudt, 1985; Berkhoudt et al., 2001; Heiss et al., 2008).

The omnivorous aquatic turtles studied to date have a very flexible (sensu Wainwright et al., 2008) feeding behaviour (Davenport et al., 1992; Lauder and Prendergast, 1992; Lemell and Weisgram, 1997; Bels et al., 1998). The common musk turtle also exhibited plasticity in food uptake kinematics. It feeds on variety of non-elusive prey and approaches the food items to a close distance prior to ingestion. The construction of the hyolingual complex in $S$. odoratus restricts the turtle's ability to ingest food via suction, but benefits its ability to re-position and manipulate food items within the oropharynx. The present study demonstrates that the common musk turtles modulate their feeding be- havior even in successive feeding events involving food items which have exactly the same consistence, size and position. The food transport kinematics differed significantly within the three individuals: one of the turtles needed about half as many transport cycles prior to pharyngeal packing as the other two. Interestingly, that was the only individual showing significant correlations between the movement of the hyoid and the head. Further studies will reveal whether this can be interpreted in the context of the learning capacity or cognitive flexibility of cryptodyran turtles (Wilkinson et al., 2007, 2009, 2010. Plasticity in the cognitive capacity of $S$. odoratus could have strongly affected its ecological potential.

\section{Acknowledgements}

Dr. Christan Beisser, Dr. Patrick Lemell, Dr. Gaberiel Bever and Richard Gemel are acknowledged for helpful comments on the manuscript and material support. Stephan Handschuh inquired the CT reconstructions. Alexander Rabanser (Department of Statistics and Decision Support Systems, Univ. of Vienna) is acknowledged for statistical advices. We would like to thank Prof. Vincent Bels and Dr. Stephan Montuelle for discussion of our work. We thank Dr. Michael Stachowitsch for language corrections. Three anonymous reviewers are acknowledged for their significant contribution in improving the manuscript. This study was supported by the Austrian Science Fund FWF P20094-B17.

\section{References}

Aerts P, Van Damme J, Herrel A. 2001. Intrinsic mechanics and control of fast cranio-cervical movements in aquatic feeding turtles. American Zoologist 41: 1299-1310.

Agassiz L. 1857. Contributions to the natural history of the United States of America. Vol. 1. Boston: Little, Brown and Co.

Bels VL, Renous S. 1992. Kinematics of feeding in two marine turtles (Chelonia mydas and Dermochelys coriacea). Pp. 73-78 in: Korsos Z, Kiss J, eds, Proceedings of the Sixth Ordinary General Meeting of the Societas Europaea Herpetologica Budapest: Hungarian Natural History Museum.

Bels VL, Davenport J, Renous S. 1998. Food ingestion in the estuarine turtle Malaclemys terrapin: comparison with the marine leatherback turtle Dermochelys coriacea. Journal of the Marine Biological Association of the United Kingdom 78: 953-972.

Bels VL, Baussart S, Davenport J, Shorten M, O`Riordan RM, Renous S, Davenport J. 2008. Functional evolution of feeding behaviour in turtles. Pp. 189-212 in: Wyneken J, Godfrey MH, Bels VL, eds, Biology of turtles. Boca Raton: CRC.

Berkhoudt H. 1985. Structure and function of avian taste receptors. Pp. 463-496 in: King AS, McLelland J, eds., Form and Function in Birds. Vol. 3. London: Academic Press. 
Berkhoudt H, Wilson P, Young B. 2001. Taste buds in the palatal mucosa of snakes. African Zoology 36: 185-188.

Bever GS. 2007. Comparative growth in the postnatal skull of the extant North American turtle Pseudemys texana (Testudinoidea: Emydidae). Acta Zoologica Stockholm 89: 107131.

Bever GS. 2009. Postnatal ontogeny of the skull in the extant North American turtle Sternotherus odoratus (Cryptodira; Kinosternidae). Bulletin of the American Museum of Natural History 330: 1-97.

Bonin F, Devaux B, Dupre A. 2006. Turtles of the world. Translated by P.C.H. Pritchard. Baltimore: Johns Hopkins University Press.

Bourret R. 1939. Reptiles et batraciens reçus au Laboratoire des Science Naturelles de l'Université au cours de l'annee 1939. Descriptions de quatre espécies et d'une variété nouvelles. Notes herpétologiques sur l'Indochine française, XVIII. 4: 5-39. Hanoi: Bull. Gen. Instr. Publ.

Bramble DM. 1973. Media dependent feeding in turtles. American Zoologist 13: 1342.

Bramble DM, Wake DB. 1985. Feeding mechanisms of lower tetrapods. Pp. 230-261 in: Hildebrand M, Bramble DM, Liem KF, Wake DB, eds, Functional vertebrate morphology 13. Cambridge, MA: Harvard University Press.

Cope ED. 1865. Third contribution to the herpetology of tropical America. Proceedings of the Academy of Natural Sciences of Philadelphia 17:185-198.

Daudin FM. 1802. Histoire naturelle, générale et particuliére des reptiles. Paris: Dufart 2: 1-432.

Davenport J, Spikes M, Thornton SM, Kelly BO. 1992. Crabeating in the diamondback terrapin Malaclemys terrapin: dealing with dangerous prey. Journal of the Marine Biological Association of the United Kingdom 72: 835-848.

Ernst CH, Barbour RW. 1989. Turtles of the World. Washington D.C.: Smithsonian Inst. Press.

Heiss E, Plenk H, Weisgram J. 2008. Microanatomy of the palatal mucosa of the semiaquatic Malayan box turtle, Cuora amboinensis, and functional implications. The Anatomical Record. Part A 291: 876-885.

Heiss E, Natchev N, Beisser C, Lemell P, Weisgram J. 2010. The fish in the turtle: On the functionality of the oropharynx in the common musk turtle Sternotherus odoratus (Chelonia, Kinosternidae) concerning feeding and underwater respiration. The Anatomical Record Part A 293: 1416-1424.

Herrel, O'Reilly JC, Richmond AM. 2002. Evolution of bite performance in turtles. Journal of Evolutionary Biology 15: 1083-1094.

Joyce W, Gauthier J. 2004. Paleoecology of Triassic stem turtles sheds new light on turtle origins. Proceedings of the Royal Society B 271: 1-5.

Karnovsky MJ. 1965. A formaldehyde-glutaraldehyde fixative of high osmolarity for use in electron microscopy. The Journal of Cell Biology A 27: 137.

Kiernan J. 2003. Histological and Histochemical Methods: Theory and practice. Third edition. New York: Oxford University Press.

Latreille PA. 1801. Histoire Naturelle des Reptiles, avec Figures Déssinnées d'après Nature. Vol. 1. Paris: Détérville.

Lauder GV, Prendergast T. 1992. Kinematics of aquatic prey capture in the snapping turtle Chelydra serpentina. Journal of Experimental Biology 164: 55-78.
Lemell P, Weisgram J. 1997. Feeding Patterns of Pelusios castaneus (Chelonia: Pleurodira). Netherlands Journal of Zoology 47: 429-441.

Lemell P, Beisser CJ, Weisgram J. 2000. Morphology and function of the feeding apparatus of Pelusios castaneus (Chelonia; Pleurodira). Journal of Morphology 244: 127-135.

Lemell P, Lemell C, Snelderward P, Gumpenberger M, Wochesländer R, Weisgram J. 2002. Feeding patterns of Chelus fimbriatus (Pleurodira: Chelidae). Journal of Experimental Biology 205: 1495-1506.

Lemell P, Beisser CJ, Gumpenberger M, Snelderwaard P, Gemel R, Weisgram J. 2010. The feeding apparatus of Chelus fimbriatus (Pleurodira, Chelidae) - adaptation perfected? Amphibia-Reptilia 31: 97-107.

Li C, Wu XC, Rieppel O, Wang LT, Zhao LJ. 2008. An ancestral turtle from the Late Triassic of southwestern China. Nature 456: 497-501

Linnaeus C. 1758. Systema naturae per regna tria naturae, secundum classes, ordines, genera, species, cum characteribus, differentiis, synonymis, locis. Ed.10. Stockholm: Holmiae.

Lyson TR, Bever GS, Bhullar B-AS, Joyce WG, Gauthier JA. 2010. Transitional fossils and the origin of turtles. Biology Letters 6: 830-833.

Natchev N, Heiss E, Lemell P, Stratev D, Weisgram J. 2009. Analysis of prey capture and food transport kinematics in two Asian box turtles, Cuora amboinensis and Cuora flavomarginata (Chelonia, Geoemydidae), with emphasis on terrestrial feeding patterns. Zoology 112: 113-127.

Natchev N, Lemell P, Heiss E, Beisser C, Weisgram J. 2010. Aquatic feeding in a terrestrial turtle: a functional-morphological study of the feeding apparatus in the Indochinese box turtle Cuora galbinifrons (Chelonia, Geoemydidae). Zoomorphology 129: 111-119.

Newman HH, 1906. The habits of certain tortoises. Journal of Comparative Neurology Psychology. 16: 126-152.

Pfaller J B. 2009. Bite force generation and feeding biomechanics in the loggerhead musk turtle Sternotherus minor: implications for the ontogeny of performance. MSc-thesis, Florida State University; Department of Biological Science.

Pfaller JB. Herrera ND, Gignac PM, Erickson GM. 2010. Ontogenetic scaling of cranial morphology and bite-force generation in the loggerhead musk turtle. Journal of Zoology London 280: 280-289.

Pritchard PCH. 1979. Encyclopedia of Turtles. Neptune NJ: TFH Publications Inc.

Reilly SM, Lauder GV. 1990. The evolution of the tetrapoda feeding behaviour: kinematic homologies in prey transport. Evolution 44: 1542-155.

Reilly SM, Lauder GV. 1992. Morphology, behavior, and evolution: comparative kinematics of aquatic feeding in salamanders. Brain, Behavior and Evolution 40: 182-196.

Richter S, Auer M, Fritz U. 2007. Variation of hyoid morphology in geoemydid terrapins. Amphibia-Reptilia 28: 148-153.

Romeis B. 1989. Mikroskopische Technik. 17th. Pp. 527-566 in: P. Böck ed. München, Wien, Baltimore: Urban u. Schwarzenberg.

Scheyer TM, Sander PM. 2007. Terrestrial palaeoecology for basal turtles indicated by shell bone histology. Proceedings of the Royal Society B: Biological Sciences 274: 18851893. 
Schneider JG. 1783. Allgemeine Naturgeschichte der Schildkröten, nebst einem Systematischen Verzeichniss der einzelnen Arten und zwei Kupfern. Leipzig: Müller.

Schwenk K. 1985. Occurrence, distribution and functional significance of taste buds in lizards. Copeia 1985: 91-101.

Schwenk K, ed, 2000. Feeding: form, function and evolution in tetrapod vertebrates. San Diego-San Francisco-New York-Boston-London-Sydney-Tokyo: Academic Press.

Smith KK. 1992. The evolution of the mammalian pharynx. Zoological Journal of the Linnean Society 104: 313-349.

Sterli J. 2010. Phylogenetic relationships among extinct and extant turtles: the position of Pleurodira and the effects of the fossils on rooting crown-group turtles. Contributions to Zoology 79: 93-106.

Summers AP, Darouian KF, Richmond AM, Brainerd EL. 1998. Kinematics of aquatic and terrestrial prey capture in Terrapene carolina, with implications for the evolution of feeding in cryptodire turtles. Journal of Experimental Zoology Part A 281: 280-287.

Van Damme J, Aerts P. 1997. Kinematics and functional morphology of aquatic feeding in Australian snake-necked turtles (Pleurodira; Chelodina). Journal of Morphology 233: 113-125.

Wainwright PC, Mehta RS, Higham TE. 2008. Stereotypy, flexibility and coordination: key concepts in behavioral functional morphology. Journal of Experimental Biology 212: 3523-3528.
Weisgram J. 1982. Claudius angustatus (Kinosternidea) - Nahrungsaufnahme. Begleitveröffentlichung $\mathrm{zu}$ wissenschaftlichen Filmen. Wissenschaftlicher Film 28: 30-35.

Weisgram J. 1985. Feeding mechanics of Claudius angustatus Cope 1865. Pp. 257-260 in: Duncker HR, Fleischer G, eds, Fortschritte der Zoologie. Stuttgart: Gustav Fischer Verlag.

Wilkinson A, Chan HM, Hall G. 2007. Spatial learning and memory in the tortoise (Geochelone carbonaria). Journal of Comparative Physiology A 121: 412-418.

Wilkinson A, Coward S, Hall G. 2009. Visual and responsebased navigation in the tortoise (Geochelone carbonaria). Animal Cognition 12: 779-787.

Wilkinson A, Kuenstner K, Mueller J, Huber L. 2010. Social learning in a non-social reptile (Geochelone carbonaria). Biology Letters 6: 614-616.

Winokur R. 1982. Integumentary appendages of chelonians. Journal of Morphology 172: 59-74.

Wochesländer R, Hilgers H, Weisgram J. 1999. Feeding mechanism of Testudo hermanni boettigeri (Chelonia, Cryptodira). Netherlands Journal of Zoology 49: 1-13.

Received: 18 June 2010

Revised and accepted: 17 January 2011

Published online: 14 April 2011

Editor: J.W. Arntzen 


\section{Appendix}

Abbreviations list

$\begin{array}{ll}\text { cbI } & \text { - ceratobranchiale I } \\ \text { cbII } & \text { - ceratobranchiale II } \\ \text { ch } & \text { - corpus hyoidei } \\ \mathrm{hg} & \text { - hypoglossum } \\ \mathrm{lj} & \text { - lower jaw } \\ \mathrm{uj} & \text { - upper jaw } \\ \mathrm{CT} & \text { - computed tomography } \\ \mathrm{FC} & \text { - fast close } \\ \mathrm{FO} & \text { - fast open } \\ \mathrm{kV} & \text { - Kilovolt } \\ \mathrm{MG} \text { phase } & \text { - maximum gape phase } \\ \mu \mathrm{m} & \text { - micrometre } \\ \mathrm{SD} & \text { - standard deviation } \\ \text { oss I } & \text { - island of ossification at the basis of cbI } \\ \text { oss II } & \text { - island of ossification at the basis of cbII } \\ \text { protr. } & \text { - protraction } \\ \text { retr. } & \text { - retraction }\end{array}$

SD - standard deviations

SEM - standard error of the mean

SO - slow open

tb $\quad$ - taste bud

$\mathrm{t}_{\mathrm{D}} \quad$ - total duration

$\mathrm{t}_{\mathrm{FO}} \quad$ - fast opening

$\mathrm{t}_{\mathrm{FC}} \quad$ - fast closing duration

$\mathrm{t}_{\mathrm{HFOB}} \quad-$ hyoid retraction delay to fast opening begin

$t_{\text {HFOE }}-$ - time interval of hyoid retraction onset relative to fast opening end

$\mathrm{t}_{\mathrm{HR}} \quad$ - hyoid retraction duration

$\mathrm{t}_{\mathrm{MG}} \quad-$ MG-phase duration

$\mathrm{t}_{\mathrm{NE}} \quad-$ neck extension duration

$t_{\mathrm{PG}} \quad$ - time to peak gape

$\mathrm{V}_{\mathrm{FC}} \quad$ - fast closing velocity

$\mathrm{V}_{\mathrm{FO}} \quad$ - fast opening velocity

$\mathrm{V}_{\mathrm{HR}} \quad$ - hyoid retraction velocity

$\mathrm{V}_{\mathrm{NE}} \quad$ - neck extension velocity 